\title{
Pedrosa, Pollock e a Arte Japonesa
}

\author{
Marcos Pedro Magalhães Rosa' \\ DOI 10.20396/eha.vil4.3426
}

Essa apresentação faz parte da pesquisa de doutorado, Os Avessos da Forma, que investiga a recepção e ressignificação por críticos e artistas brasileiros, das tendências chamadas de Tachismo, Expressionismo Abstrato, Abstracionismos Informais.

Essa recepção ocorreu entre 1957 e 1960 e correspondeu a uma modificação geopolítica, na qual os Estados Unidos começaram a se afirmar, nas Bienais de São Paulo como uma potência artística, com Nova lorque ladeada por Roma, Paris e Londres como centros internacionais da arte. Nessa ocasião, eles trouxeram uma mostra de expressionismo abstrato e a primeira retrospectiva do Jackson Pollock, que havia morrido no ano anterior. Após a Bienal, a mostra circulou a Europa e tanto esse estilo, quanto o pintor destacado foram apresentados como representativos de éthos estadunidense na pintura.

Do outro lado do Atlântico, a França, que causava frisson nas Bienais de São Paulo, não conferia destaque institucional a essas tendências. Suas instituições para as artes visuais contavam com uma verba pública restrita. O teatro (símbolo de uma glória pretérita à guerra para os franceses) e a restauração dos monumentos destruídos pela guerra tinham prioridades no orçamento governamental. As artes do passado ganharam prerrogativa naquele país e os funcionários dos museus, formados prioritariamente na Escola do Louvre e na Escola do Patrimônio, se entendiam como conservadores e eram comprometidos com a ideia de manutenção do patrimônio histórico. Para Jean Cassou, por exemplo, curador do Museu de Arte Moderna de Paris, acreditava que promover a arte contemporânea era apoiar artistas já consagrados, como Picasso, Bracque, Giacometti e Leger².

A despeito da França, a IV Bienal de São Paulo foi inteira consagrada a essas tendências informais e os franceses perderam, pela primeira vez, o prêmio de melhor pintura estrangeira. No ano seguinte, eles perderam, também pela primeira vez, o prêmio de melhor pintura da Bienal de Veneza. Em função disso, eles iniciam um processo de centralização das atribuições culturais nas mãos do ministro André Malraux, recusam-se a participar da V Bienal e gradativamente forjaram uma nova narrativa da arte informal, na qual o francês Jean Fautrier figurava como precursor des-

Doutorando em História da Arte - IFCH/UNICAMP com projeto financiado pela FAPESP.

2 DOSSIN, Catherine. The Rise and Fall of American Art, 1940's-1980's.2015. pp.103-105. 
sas tendências e nacionalizaram alguns pintores estrangeiros vinculados a esse estilo, como Hans Hartung ${ }^{3}$.

Em 1959, a imprensa e a crítica especializada relataram a sensação de que, na $V$ Bienal, apelidada de Bienal Tachista, as características regionais haviam se diluído e que não era possível saber onde começava e onde terminava a representação de cada país. Nesse período de consolidação de um estilo transnacional representado pelas tendências informais, Mário Pedrosa, reticente às reformas empreendidas pela França e à ofensiva imperialista que esse país estava impondo à cultura brasileira e à de outros países periféricos, aproximou-se do Japão.

Para esse crítico, em 1957 Pollock era um dos principais motivos para visitar a Bienal de São Paulo e diferente da maioria dos intelectuais brasileiros, ele já era familiarizado com a produção desse artista, sobre quem já havia escrito em 1951․ Em 17 de janeiro de 1958, ele defendeu a decadência do tachismo, que ele caracterizava como uma "arte de manchas e borrões, meras explosões temperamentais (no melhor dos casos) ou aglomerado automático de coisas, tintas a escorrer, estopa, arame e tudo o que se quiser; amassado sobre uma tela". Pollock, no entanto, "que se" queria "dar como pai do tachismo", só seria comparável na Bienal de 1957 com as obras do pavilhão japonês, em especial com a pintura de Yukei Tejima. Ambos seriam representativos de uma tendência "caligráfica" que estaria suplantando o tachismo ${ }^{5}$. Naquele momento, o crítico acompanhava também a produção de arte informal europeia, especialmente a francesa e acreditava que se tratava de uma pintura hedonista, conformada e reprodutora de cacoetes acadêmicos. A arte norte-americana seria uma produção de revolta anárquica, feita por artistas que gozariam de extrema liberdade, mas que estariam impossibilitados de participar, como sujeitos históricos, dos processos mais amplos da vida cultural ${ }^{6}$.

Boa parte do que Pedrosa escreve sobre arte japonesa está ancorada no livro de Owen E. Hollloway, publicado também em 1957 e a imagem que seus textos criam da ilha é a de um local no qual as artes gráficas e a caligrafia teriam o melhor desenvolvimento do planeta, ancorados na existência de temas comuns a todas as classes sociais japonesas e ao redor dos quais as artes gravitariam: a poesia e os elementos da natureza. A existência desses temas faria do extremo oriente um contexto comparável ao do renascimento italiano, no qual os assuntos repetidos pelos artistas

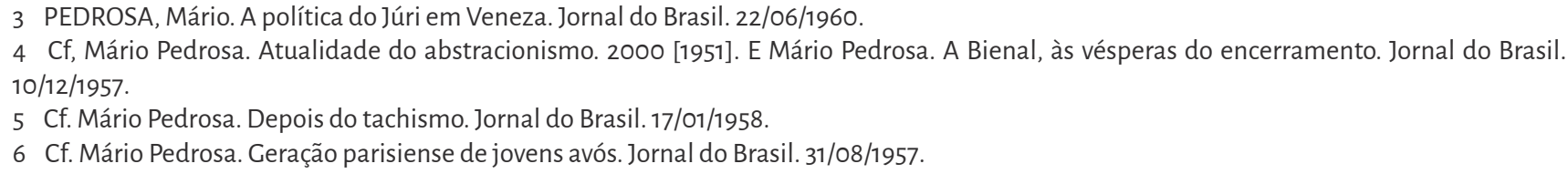


possibilitariam a emergência de padrões em torno dos quais as artes girariam, aquilo que Pedrosa, ancorado em Burkhart chamou de "estilos". A arte japonesa seria, portanto, uma arte produzida por artistas em profunda comunhão com a sociedade e valorizaria o domínio artesanal e a reprodutibilidade das obras de arte. Os ocidentais, por outro lado, atravessados pela mecanização e pela transformação da arte em mercadoria, valorizariam a raridade da obra e do artista. Daí emergiria o tachismo, cujas obras não passariam de um signo que aponta apenas para o seu próprio criador, como uma assinatura pessoal7.

Especificamente sobre o papel da caligrafia no oriente, a admiração nipônica por essa arte envolveria, segundo Pedrosa, até mesmo os iletrados, eliminando a possibilidade de que seu valor fosse decantado do significado das palavras. Para explicar o papel dessa arte naquela sociedade, Pedrosa recorreu mais uma vez a Holloway:

Holloway compara esse fenômeno típico das artes gráficas japonesas ao que se passa com a poesia dos hai kai: 'há, diz ele, por trás do assunto ostensivo um conteúdo predominante (overruling) dentro do qual aquele tem de ser interpretado". E em que consiste? "No sentido da estação e suas vistas e sons específicos, e a fauna e a flora, e os ritos sociais. Tudo aí nesse contexto, vejam, ultrapassa o indivíduo, o contingente, o puro gosto pessoal, a procura frenética e de algum modo irresponsável da originalidade pela originalidade.

[...]

Isso significa que a atitude em face das coisas e dos seres - tanto no clássico como no povo - não é crítica, nem histórica, nem ilustrativa ou lógica. É perceptiva, experimental, objetiva (e é poética se esta se pode inserir, como creio que pode, na conceituação básica e global-fenomenológica).

$[\ldots]$

A poesia dos hai-kai e a beleza do estilo caligráfico japonês partem de uma mesma experiência fundamental: vistas e sons da natureza. Desta experiência participam letrados e iletrados: daí a permanência numa forma afinal puramente abstrata daqueles signos caligráficos de uma vitalidade plástica que atravessa épocas e modas ${ }^{8}$.

Se Pollock parece ter aguçado a visão do crítico para a arte japonesa, foi nesta última que ele encontrou a ideia de caligrafia como um adjetivo, capaz de se referir tanto às obras orientais quanto à do pintor norte-americano. Pedrosa caracteriza esse tipo de quadro pela "pincelada que vai servir de modo tão específico na pintura tanto da China como do Japão" e que deve ser apreendida "à parte, num exercício de punho que lembra o do violinista no manejo de seu arco" e que se mantém 
prenhe de "significações virtuais ou latentes". O gesto que materializa a escrita, apesar de certa aparência de improvisação, é decisivo e irrevogável. "As rasuras, correções, retoques, repassagens são imprevisíveis":

Mas faz parte da natureza mesma da arte de signos a unicidade do movimento ou do gesto que os cria. Despedida de sua significação de palavra escrita, a caligrafia liberta o signo, e, como o liberta, torna-o indissoluvelmente preso ao movimento ou ao golpe do pincel: transforma-se em único, em signo plástico. É que o signo para ser válido em sua significância não literal, não discursiva não pode ser equívoco ou indeciso ou ambíguo, tanto na origem quanto no contexto gráfico onde se situa. Só é múltiplo de significações quando funciona como letra, como convenção monossilábica, como palavra - isto é, tem um sentido lógico preciso. E aí está porque quando o signo surge em sua pureza potencial, fora de qualquer contexto verbal linguístico, para ser significante e único no plano do símbolo estético, é sempre fruto de uma violência inicial necessária, de um impulso energético que Ihe dá nascimento: daí o seu caráter direto, imediatista, coeso, por assim dizer "repentino, no aparecer, - é irremediável, irrevogável, irreparável"9.

Ao longo dos próximos meses Pedrosa lapidará essa ideia. No dia 8 de fevereiro de 1958 ele publicará um artigo que reitera, no ocidente, a decadência do tachismo em função de uma arte de “inspiração gráfica”, que só se faria presente na pintura e descenderia, no ocidente, de Klee. Ele cita os artistas que acreditava já estarem mobilizados por essa tendência: Hartung, Soulages, Védova e Pollock. Os dois primeiros são tratados com ressalvas. Hartung "parece num impasse, a debater-se entre a pureza ancestral do signo e a necessidade por assim dizer cultural ou social de superá-lo", Soulages "não se entrega, largado, ao primeiro movimento do braço ou gesto físico solto. Ele corrige o impulso inicial, o ritmo do próprio braço, (como se com uma brocha caiasse vasta parede) já que não admite nenhum trabalho criador resultante de mero produto do acaso ou, concretamente, da simples descarga fisiológica do movimento ou do gesto do corpo ou de parte deste.

Védova seria o grande herdeiro do futurismo e sua pintura seria "tão signográfica" que quase eliminaria a cor, compondo a tela numa "dinâmica físio-mental ou espiritual". O movimento de seu punho teria algo de "episcopal". Seria "como uma benção" e haveria, na composição "uma espécie de prédica", ou de projeto.

Pollock figura mais próximo dos japoneses (Pedrosa compara a tela abismo de Pollock com o desmoronamento de Waichi Tsudaka), ambos empreenderiam uma pintura que seria "de início, um signo fulminante, um raio que fende o espaço: impossível de ser detido". Pollock teria "horror ao

9 Mário Pedrosa. Da Caligrafia ao Plástico. Mário Pedrosa. 01/01/1958. 
estável, isto é, ao quadrado". Se os japoneses tentavam usar a caligrafia e "escapar ao signo ideográfico, no norte-americano isso não seria possível, pois diante dele só haveria o vazio. Ele, "bom filho do extremo ocidente", não teria um projeto anterior ao quadro, não partiria de uma tradição. Ele marcharia do nada para o desconhecido. E Pedrosa conclui:

O perigo dessa arte no Ocidente é o seu hermetismo individualista. Este, contudo, já que se exprime numa sucessão rítmica de signos em ritmo linear bidimensional num Pollock, e que por ser linear não deixa ver um fim, um epílogo, e em ritmo espacial mais arquitetônico, num Védova - alcança a universalidade. No pintor americano, a universalidade perene de um símbolo trágico; no italiano, a universalidade de uma operação mágica de decantação ou de profecia, válida provavelmente sob todos os climas de nossa época ${ }^{10}$.

Boa parte da produção de Pedrosa sobre a pintura abstrata é marcada por uma perspectiva culturalista, na qual cada tradição nacional, vinculada a um contexto social específico, confere o sentido onde determinada obra e artista são descritos. É nesse momento de aproximação com a arte japonesa que a característica culturalista desses textos de Pedrosa começa a se esmaecer em função de uma interpretação pan-ocidental. Embora permaneça um pouco dessa perspectiva antiga na forma pela qual encara Védova e Pollock, o título do artigo "O signo no ocidente" do texto de 8 de fevereiro marca o início de um processo que culmina no ensaio "Da abstração à auto expressão" de 12 de dezembro de 1959. Neste ensaio, Pedrosa oferece uma interpretação sobre a pintura atual e não há separação entre tachismo e arte caligráfica. Os pintores citados anteriormente voltam a comparecer no texto, mas contracenam à luz de um diagnóstico universalista.

A transformação da perspectiva de Pedrosa acompanha uma série de mudanças na vida do crítico, da posição do Brasil no mundo das artes e do caráter da arte abstrata não-geométrica pelo mundo. Em 1958 Pedrosa fora escolhido pela AICA como pesquisador da UNESCO numa viagem ao Japão. O crítico descreveu a importância de sua viagem como vinculada à "confluência de culturas entre o Oriente e o Ocidente", um problema que atravessaria arte, política e economia e da qual dependeria "o próprio futuro da civilização"11. A escolha de Pedrosa, um crítico brasileiro para essa missão, parece encontrar contrapartida no próprio universo local. De volta, Pedrosa anuncia os planos de edição de uma revista internacional de arte, publicada alternadamente entre o Brasil, o Japão e a Itália e inicia os preparativos para o congresso internacional de Críticos de Arte no Brasil12, moti-

\footnotetext{
10 Mário Pedrosa. O Signo no Ocidente. Jornal do Brasil. 08/02/1948

11 Mário Pedrosa. Arte: Ocidente-Oriente. Jornal do Brasil. 29/07/1958.

12 Ferreira Gullar. Congresso de Brasília entusiasma os europeus. Jornal do Brasil. 30/04/1959.
} 
vado pela construção de Brasília e subsidiado pelo Itamaraty, por Francisco Matarazzo sobrinho e por Niomar Moniz Sodré ${ }^{13}$. O congresso é apresentado pelo próprio Pedrosa como o ápice histórico da crítica de arte no Brasil ${ }^{14}$. A adoção, portanto, de uma perspectiva universalista parece mais adequada a essa nova posição que Pedrosa sentia que ele próprio e o Brasil vinham conquistando no mundo das artes.

Por outro lado, os relatos de Pedrosa no Japão, publicados pelo Jornal do Brasil ao longo dos anos 1958 e 1959, são marcados por uma perspectiva, ao mesmo tempo, exotisante e idealizada. A ilha nipônica seria o país do mundo onde se levou mais longe "o problema crucial da integração do espírito na vida cotidiana". Ele seria a "pátria eleita do que vagamente no Ocidente se vem chamando de integração das artes"15 e o crítico o descreve os japoneses em uma série de textos, explicando aos brasileiros as diferenças nas concepções brasileiras e japonesas de respeito, de corporalidade, de temporalidade, de ética, etc. Se, por um lado, os japoneses figuravam como bons selvagens, a expansão do tachismo poderia tornar a ilha um triste trópico. Em um relato sobre as exposições que visitara, Pedrosa comentou uma mostra chamada "da arte internacional de uma nova era - Informal e Gutai". A mostra teria o "espírito de salada imitativa”. Teria Tapies, teria Kline e os "japoneses do Gutai" ainda não teriam saído da "fase de escolares que imitam a maneira de um Pollock (...), de um Burri (...) ou mesmo de um Mathieu.". A exposição fora organizada por Michel Tapié, que seria um “desses parisienses espertos que, associados a marchands de tableaux, inventam 'ismos' e descobrem 'gênios' todos os dias, pois esta é a profissão deles" ${ }^{16}$. No Brasil, a situação não parecia a Pedrosa muito diversa, pois, segundo ele, todos os artistas que se apresentaram no "Salão Moderno" de 1959 passaram ao tachismo, em consonância com o que poderia ser visto na Bienal daquele ano:

A primeira impressão - e a mais profunda - que nos dá todo esse tachismo, que enche tão longas paredes, é de ser produto da moda: ser inconsciente, se, todavia, excetuarmos as telas de Manabu Mabe, as de Fukushima, de matéria tão requintada, e mesmo de Tanaka, apesar de sua fraqueza... ${ }^{17}$

Não à toa, o último parágrafo do Ensaio "Da abstração a auto expressão", também publicado no ano de 199, é dirigido diretamente aos brasileiros, para que estes "recém-chegados à escola" tachista se precavenham contra o maior risco desse estilo: a "gratuidade vazia". Embora Védova,

\footnotetext{
1358 críticos de 18 países farão congresso em Brasília, São Paulo e Rio. Jornal do Brasil. 20/05/1959.

14 Mário Pedrosa. O congresso internacional diante dos críticos. Jornal do Brasil. 17/06/1959.

15 Mário Pedrosa. Monumento ao imigrante japonês. Jornal do Brasil. 12/06/1958.

16 Mário Pedrosa. Arte - Japão \& Ocidente. Jornal do Brasil. 17/09/1958.

17 Mário Pedrosa. O Salão Moderno. Jornal do Brasil. 18/11/1959
} 
Pollock e Hartung figurem lado a lado nesse ensaio, citados como exemplares de um tipo contemporâneo de artistas, o pintor que recebe os golpes mais pesados da artilharia de Pedrosa é Ceorge Mathieu, que funciona como epítome de toda essa tendência. É nesse pintor francês que Pedrosa diagnostica o sentido aristocrático e gratuito de uma arte que só revela a própria personalidade do artista. O oposto, portanto, da arte japonesa, na qual o sentido de coletivização viria em primeiro lugar.

Ao seguir essa linha interpretativa, Pedrosa diagnostica que a gravura teria se desenvolvido melhor no Japão do que em qualquer lugar do mundo. Essa técnica demandaria "humildade do artista", por se propor à fabricação de um objeto reprodutível a exaustão e, portanto, destinado à multidão. No Ocidente essa humildade seria encarada como "servidão":

No ocidente, com efeito, nunca se pôde levar a cultura a muitos, sem que se a fizesse incontinenti baixar ao 'nível desses muitos'. Tampouco nunca se pôde reconciliar ali quantidade com qualidade, e daí também o fato de parecer 'inerente' à tarefa mesma do gravador certo sentido de servidão ${ }^{18}$.

Enquanto no Japão a valorização do domínio artesanal seria central, a base "industrial-comercial" do ocidente determinaria o "culto da falsa originalidade": o processo mecânico de reprodução e a "deferência à natureza democrática da produção em massa" rebaixaria, entre nós a valorização e a qualidade das artes gráficas e elevaria, por outro lado, o "valor fetiche atribuído a algo fundado em princípios opostos, quer dizer, a esboços 'originais dos próprios artistas'”. Nossa comunidade "de negócios" atribuiria uma "superioridade pecuniária a esses objetos feitos "à mão" em detrimento daqueles reprodutíveis mecanicamente.

18 Mário Pedrosa. Artes Gráficas no Japão. Jornal do Brasil. 15/01/1958. 


\section{Referências bibliográficas:}

AVELAR, Ana Cândida. Controversies of a Juror: Alfred Barr Jr at the 4th São Paulo Bienal. Third Text, 26. 2012.

BRITO, Ronaldo. Neoconcretismo: Vértice e ruptura do projeto construtivo brasileiro. São Paulo: Cosac \& Naify. 1999.

DOSSIN, Catherine. The Rise and Fall of American Art, 1940's - 1980's: A geopolitics of Western Art Worlds. Burlington: Ashgate. 2015.

GUILBAULT, How New York Stole the Idea of Modern Art: abstract Expressionism, freedom, and the Cold War. Chicago: University of Chicago Press, 1985

PEDROSA, Mário. “Atualidade do abstracionismo". In: ARANTES, Otília. (Org.). Mário Pedrosa: Modernidade cá e lá. São Paulo: EDUSP. 2000 [1951]

PEDROSA, Mário. “Arte - Japão \& Ocidente” in: ARANTES, Otília (org.). Mário Pedrosa: modernidade cá e lá. São Paulo: EDUSP. 2000 [1958].

PEDROSA, Mário. "Crupo Frente" in: ARANTES, Otília. Mário Pedrosa: acadêmicos e modernos. São Paulo: EDUSP.2004 [1955].

Pedrosa, Mário. "Pintura Brasileira e Costo Internacional". In: ARANTES, Otília. Mário Pedrosa: Acadêmicos e Modernos. São Paulo: EDUSP. 2004 [1957]. P. 281.

Pedrosa, Mario. “Da abstração à auto expressão". In: Mammì. L. (org.). Mário Pedrosa. São Paulo: Cosac \& Naify. 2015 [1959].

ROSA, Marcos Magalhães. O Espelho de Volpi: o artista, a crítica e São Paulo nos anos 1940 e 1950. Dissertação de Mestrado apresentada ao Instituto de Filosofia e Ciências Humanas - UNICAMP. 2015.

ROSA, Marcos Magalhães. A Tale of Masters and Islands: Volpi claimed by Mário Pedrosa. Sociologia e Antropologia v.8. 2018. 